
History Research

Reseña

\section{Anne Dubet y Sergio Solbes Ferri. El rey, el ministro y el tesorero. El gobierno de la Real Hacienda en el siglo XVIII español. Madrid, Marcial Pons, 2019, 576 pp. ISBN: 9788416662678.}

Estamos ante un libro cuya nada desdeñable extensión se ajusta a la larga trayectoria investigadora recorrida por sus dos autores en el carril de los estudios sobre la Hacienda del siglo xviII. La riqueza de las fuentes utilizadas, así como su amplio repertorio bibliográfico, no hacen más que corroborar este hecho. Asimismo, la obra no es tan solo una suma de la investigación que han desarrollado durante estos años y de la que es fruto su producción científica, sino que ahonda en cuestiones apenas tratadas hasta ahora, comprende nuevas franjas cronológicas y aventura los cambios del siglo xIX, convirtiéndose sin duda en una obra de referencia para los que nos enfrentamos al laberinto de la Hacienda borbónica.

La primera de las dos partes en la que se halla dividida la obra está dedicada a la conformación de la Tesorería General desde sus albores hasta 1799. Más de trescientas páginas la convierten en la más extensa. En ella encontramos un exhaustivo análisis de las instrucciones y reformas que se dan a lo largo de este siglo, así como de sus consecuencias. Todo ello ofreciendo una historia de su evolución que se halla siempre acompañada y completada por el análisis de los cambios políticos e institucionales y que otorga un espacio privilegiado a los grandes actores, como son los ministros y los hombres de negocios.

En sintonía con lo que hemos visto en otros de sus trabajos, nos encontramos con una apuesta clara de los autores por el papel de los individuos en el devenir del gobierno de la Real Hacienda, así como por el esclarecimiento de sus objetivos, sus alianzas y su visión del juego. Conceptos como la fidelidad, el trabajo en equipo y las habilidades de los gestores jalonan el hilo conductor del libro, con epígrafes como el de «El talento de Grimaldo y Amelot» (p. 66) o "Campillo, Ensenada y las nuevas reglas del juego (1741-1753)» (p. 207).

Uno de los puntos centrales de la obra es el del control fiscal del Estado, relacionado con la construcción del andamiaje de la Tesorería General, pero también con otros de los cambios que se suceden a lo largo del siglo xviII, como por ejemplo los realizados en los sistemas de recaudación o en el refuerzo del eje intendente-contador-tesorero. Ligado a ello, también se relata el proceso hacia un mayor control financiero, y se hace desde la complejidad interna de las instituciones, como la Contaduría de la Intervención o la Tesorería de la Ordenación, o desde los planes clave desarrollados por ministros como Ensenada o Lerena. Y todo ello en un camino en el que los autores también se adentran en las redes establecidas entre los hombres de negocios y la Hacienda Real, como se ve por ejem- plo al tratar la cuestión de la "constelación» de Goyeneche (p. 161), o en su análisis de las fricciones entre las oligarquías y los gestores territoriales.

La deuda y el uso habitual del préstamo como recurso del Estado es otro de los puntos destacados del libro, al igual que lo son el fraude y su visibilidad, analizados a través de cuestiones como los pagos «a buena cuenta» o el tráfico de efectos de la Tesorería Mayor. El volumen de la deuda, las aspiraciones a su control y las soluciones planteadas con este objetivo cobran relevancia en diversos capítulos, y se desarrollan a nivel técnico en la segunda parte del libro, de tal forma que las políticas de control de cuentas se plasman en las nuevas fórmulas de gestión y de ordenación aplicadas por los tesoreros.

La proyección hecha por los autores sobre estas cuestiones nos conduce hacia una conclusión: la mejoría del control y de la prevención de los malos usos de los créditos, con un período clave, el de Ensenada, que abre la puerta hacia un final de siglo en el que se puede hablar sin titubeos de fortaleza de la Tesorería y de gran mejoría en la gestión de los dineros. Asimismo, la explicación del control centralizado y del sistema de gestión territorial del gasto ayuda al lector a entender en qué consiste esa mejoría, reflejada en aspectos diversos: las cajas, la intervención, las mesas del negociado de Hacienda, el Real Giro, etc.

El primer bloque culmina con un cuarto y último capítulo que presenta de nuevo un trinomio de peso (Floridablanca, Lerena y Soler) y que recoge otros temas de gran interés, como el proyecto de unión del gobierno de las haciendas peninsulares, insulares e indianas. Podemos decir que el capítulo corona la evolución del control de la Hacienda, dejándonos el sabor de la mayor intervención y el mayor dominio sobre las rentas provinciales y los administradores de rentas por parte de un Estado al que debe darse cuenta de todo y que intenta reforzar su poder con herramientas como las juntas provinciales o a través de la modificación de las relaciones de poder entre la Corona, los agentes del rey y las élites locales.

Este gran envoltorio, que es la primera parte y que recoge nociones fundamentales para llegar a desentrañar la consolidación de la Tesorería, descubre una segunda de 170 páginas donde las que hablan son las cifras. La definición de los ingresos y los gastos de la Hacienda, el análisis de sus contenidos y su distribución territorial ayudan a comprender todo lo relatado anteriormente. Además, los autores no se olvidan de temas de alto interés vinculados a las cuentas, como son los asientos y la provisión del ejército. En general, la minuciosidad de este bloque y la ejemplificación de la teoría son los culpables de que este sea un libro para todos los públicos, también para aquellos que son nuevos en estas lides.

Los cambios técnicos llevados a cabo en la Tesorería no pueden entenderse sin conectarlos a los movimientos políticos, pudiéndose ver a través de esta conexión qué fraudes generan cierta tolerancia y cuáles deben atajarse. Si antes nos 
hemos referido al fraude y al control de cuentas como puntos destacados de esta obra, gracias a este segundo bloque podemos ver conectada la parte técnica con la política. Buen ejemplo de ello es cómo la mayor preocupación por la limitación y el control de la deuda corriente llevó a la formalización de "estados de fondos y cargas», a cuya realización estuvo obligado el tesorero general. Una preocupación que más tarde supuso la modificación de la ordenación del cargo y de la data en las cuentas de la Tesorería.

El quinto capítulo del libro define qué es y qué comprende el concepto de cargo contable, para ir después desgranando sus partidas y la justificación de las cuentas, los diversos grados de abstracción de la cuenta de la Tesorería y la evolución de un método que empieza a uniformizarse desde finales de 1753. También se detalla el incremento del dominio del tesorero general sobre varios aspectos, pero sobre todo en la relación con los tesoreros de rentas, y dedica también un espacio a la gestión de estas, con especial atención a la renta de las rentas, la del tabaco. Se explican conceptos que deben tenerse muy en cuenta, lo que ayuda a comprender la complejidad del análisis de las cuentas: entrada por salida, la asunción de manera ficticia de los ingresos por parte del tesorero general, la deuda corriente, etc.

En el capítulo sexto, se define lo que es la data, cómo se distribuye y qué método se practica, valorando la justificación de las cuentas y todo el conjunto de documentos que sirven para descargar al autor de la cuenta, así como la mejoría de la información que recibe el Tesorero General desde 1759. Merece la pena destacar el tratamiento que se da a las clases de gasto y el desglose exhaustivo con ejemplificaciones de su distribución territorial y con ejemplos de cargo de los tesoreros generales.

El último capítulo de este segundo bloque versa sobre la cuenta única del tesorero general dentro de un marco cronológico de estabilidad, y otorga en su interior un espacio propio a temas tan poco difundidos como el de la ordenación. Este discurso se ve apoyado en diversos cuadros, como el 7.4, que representa el balance de cuentas del período 1755-1764 y que nos ofrece una imagen presupuestaria muy detallada.

Con el objetivo de dar a conocer los entresijos de la historia de la Tesorería General, los autores utilizan tecnicismos que podrían dificultar la comprensión a los neófitos, pero estos son explicados a lo largo del trabajo (la formulación del cargo y la data, la cuenta única...), haciendo así más asequible su entendimiento. Si bien algunas partes del libro requieren de una lectura pausada para desgranar su contenido, la existencia de esta adecuada ejemplificación y de quince páginas de anejos muy prácticos compensa estas dificultades. Del mismo modo, el índice onomástico facilita la atención a la diversidad de personajes que transitan por el manejo de los dineros de la Real Hacienda a lo largo del siglo xviII.

Solo podemos finalizar señalando que la mejor reseña de este libro la encontramos en el epílogo, donde los autores reflejan su voluntad: hacer una historia política, económica, cultural y técnica de la Tesorería General. Una historia que refiere actores de todas las esferas políticas y económicas del siglo xviI y que navega por las entrañas de la Real Hacienda para acercarnos a su comprensión. También es una historia que se sostiene bajo un título que representa el primero de los numerosos trinomios que encontramos en la obra: el rey, el ministro y el tesorero.

Un último valor añadido para los investigadores: si bien demostrar que la Tesorería General es un cuerpo vivo, dinámico y cambiante es algo que corre por cuenta de los autores, estos invitan a los lectores a recoger el testigo planteando cuestiones en las que aún debe profundizarse. Ese aliento, presente a lo largo del libro, es sin duda una de sus marcas de identidad.

Ana María Coll Coll Universitat de les Illes Balears

https://doi.org/10.33231/j.ihe.2020.01.007 